\title{
O PODER JUDICIÁRIO RECONHECENDO OS DIREITOS DOS ANIMAIS AO PROIBIR O CAMPO DE CONCENTRAÇÃO ANIMAL
}

\author{
THE JUDICIARY RECOGNIZING THE RIGHTS OF ANIMALS PROHIBIT THE \\ FIELD OF CONCENTRATION ANIMAL
}

\section{Othoniel Ceneceu Ramos ${ }^{1}$}

RESUMO: O presente artigo objetiva, por meio da análise do acórdão proferido pelo egrégio Tribunal de Justiça do Estado de Minas Gerais, em recurso de apelação interposto pelo Ministério Público de Minas Gerais, demonstrar o importante papel do Judiciário na proteção dos animais no direito pátrio. O recurso foi motivado por sentença que julgou improcedente a ação civil pública, proposta pelo órgão ministerial, que visava impedir práticas cruéis de extermínio de animais abandonados ou considerados doentes realizadas pelo Poder Público Municipal. Sob o argumento de combater a proliferação de doenças e garantir a saúde pública, o município de Belo Horizonte praticou atos de crueldade contra esses animais. Na apreciação do recurso, os desembargadores, por maioria, julgaram parcialmente procedente a pretensão ministerial, estabelecendo em seus votos um verdadeiro magistério acerca do tema.

PALAVRAS-CHAVE: Animais; Extermínio; Improcedência; Práticas Cruéis; Procedência parcial; Recurso.

ABSTRACT: This article aims, through an analysis of the judgment of the Honorable Court of the State of Minas Gerais in an appeal filed by prosecutors of Minas Gerais, demonstrating the important role of the judiciary in the protection of animals at the paternal law. The appeal was motivated by a judgment which dismissed the Civil Action proposed by the Public Ministry that was intended to prevent the cruel practice of extermination of abandoned animals or ill considered conducted by the Municipal Government. Under the argument to prevent the spread of disease and ensure public health, the municipality of Belo Horizonte committed acts of cruelty to these animals. On hearing of the appeal, the justices, by a

\footnotetext{
${ }^{1}$ Mestre em Direito pela Escola Superior Dom Helder Câmara; Bacharel em Direito pelo Centro Universitário de Belo Horizonte - UNIBH (2012); Especialista em Educação; Especialista em Educação Matemática; Licenciatura Plena em Matemática pelo Centro Universitário de Belo Horizonte (2001). E-mail: othocrj@yahoo.com.br
} 
majority, judged in part the ministerial claim, and establishing in their votes a true teaching on the subject.

KEYWORDS: Animals; Appeal; Cruel practices; Dismissal. Extermination; Partial validity.

\section{INTRODUÇÃO}

Atualmente, algumas famílias têm destinado parte de seu afeto aos animais de estimação a ponto de tratá-los como verdadeiros membros da família. Entretanto, nem todos os animais possuem a mesma sorte, pois muitos são maltratados e, quando não entregues ao órgão municipal que cuida do controle de zoonoses, são abandonados pelas ruas, ficando expostos a doenças - alguns ainda são vítimas de atropelamento e outros recolhidos pela municipalidade.

Este artigo busca analisar um acórdão julgado pelo Tribunal de Justiça do Estado de Minas Gerais que apreciou o destino dos animais de rua da capital mineira recolhidos pelo Centro de Controle de Zoonoses - CCZ. Trata-se de um estudo de caso que objetiva trazer a atuação do Poder Judiciário no que se refere à proteção e ao reconhecimento dos direitos dos animais.

Os animais, ao serem recolhidos pelo CCZ, eram colocados na companhia de outros animais, estando esses sadios ou não. Aqueles que estavam saudáveis aguardavam alguém reclamar por eles; não ocorrendo isso, eram, juntamente aos demais, sacrificados. Dessa forma, indaga-se: não teriam os animais direitos? E esses direitos não deveriam ser respeitados pela própria Administração Pública Municipal e seu respectivo órgão de controle de zoonoses?

A evolução do entendimento social acerca dos animais como sujeitos de direito é evidente, entretanto, esse entendimento nem sempre foi aceito. Considerados "coisas" nos tempos de Roma (MACHADO, 2012, p.909), hoje os animais adquiram não apenas os direitos tipificados em normas jurídicas, como também as garantias para o seu exercício.

Com o surgimento das organizações não governamentais - ONGs de proteção ao animal, o aparelhamento, a qualificação do Ministério Público e a contribuição da mídia, os 
animais em geral, sejam pertencentes à fauna brasileira ou à fauna exótica ${ }^{2}$, ganharam importantes aliados na luta por direitos reconhecidos e respeitados.

Em Minas Gerais, o MPMG, como fiscal da lei, tem contribuído por meio de ações civis públicas com a manutenção e promoção desses direitos e garantias, e as ONGs, utilizando-se dos veículos de comunicação, têm denunciado as práticas de tortura realizadas não só pela sociedade civil, como também pelo próprio Estado. Com base nisso, a população, as ONGs e o Ministério Público vêm, com o intuito de defender os direitos dos animais, ajuizando ações no Poder Judiciário, solicitando que o mesmo obrigue as pessoas, sejam essas físicas ou jurídicas, a cumprirem as leis que concedem tais direitos.

Um bom exemplo disso será visto neste artigo, no qual o Poder Judiciário mineiro contribuiu para o respeito e a proteção dos animais que se encontram no CCZ, apreendidos ou doados, frente aos diversos argumentos jurídicos apresentados pelo município de Belo Horizonte.

\title{
1 ESTUDO DO RECURSO DE APELAÇÃO Nº 1.0024.03.038441-6/002
}

\begin{abstract}
APELAÇÃO CÍVEL No 1.0024.03.038441-6/002 - COMARCA DE BELO HORIZONTE - APELANTE(S): MINISTÉRIO PÚBLICO DO ESTADO DE MINAS GERAIS - APELADO(A)(S): MUNICÍPIO DE BELO HORIZONTE, LITISCONSORTE: SOCIEDADE MINEIRA PROTETORA DOS ANIMAIS RELATOR: EXMO. SR. DES. CAETANO LEVI LOPES - RELATOR PARA O ACÓRDÃO: EXMO SR. DES. FRANCISCO FIGUEIREDO.
\end{abstract}

O caso em estudo trata-se de um recurso de apelação interposto pelo Ministério Público do Estado de Minas Gerais - MPMG em face da r. sentença que julgou improcedente sua pretensão aduzida em uma ação civil pública - ACP. Tal ação visava impedir o Centro de Controle de Zoonoses da capital mineira (Belo Horizonte) de praticar métodos considerados cruéis e desumanos em cães, gatos e outros animais apreendidos pelo mesmo.

\footnotetext{
${ }^{2}$ A portaria 93 do Ibama de 1998 , em seu art. $2^{\circ}$, incisos I, II e III, conceitua a fauna silvestre brasileira como sendo constituída por animais provenientes das espécies nativas, migratórias e quaisquer outras, aquáticas ou terrestres, tendo seu ciclo de vida dentro do território brasileiro. Já a fauna silvestre exótica é conceituada como a dos animais cuja localização não pertence ao território brasileiro e aqueles animais inseridos pelo homem. Por fim, a fauna doméstica é classificada como aquela dos animais que por meio de processos tradicionais e sistematizados de manejo e/ou melhoramento zootécnico tornaram-se domésticas, apresentando características biológicas e comportamentais de estreita dependência do homem.
} 


\subsection{AS RAZÕES MINISTERIAIS}

No recurso de apelação, o MPMG salientou que os fatos aduzidos na ACP (maus tratos e práticas cruéis) foram comprovados por meio do procedimento administrativo ${ }^{3}$ de número 53/03. Nele teriam sido demonstrados fatos ligados a maus-tratos, bem como a sacrifícios de animais recolhidos pelos funcionários do CCZ, por meios cruéis.

Posterior ao procedimento administrativo, uma vistoria no CCZ foi realizada. Nessa vistoria, verificou-se que as práticas cruéis, inclusive o extermínio de animais, ainda não haviam sido interrompidas. O processo administrativo 53/03 e a vistoria posterior demonstraram que os animais apreendidos eram conduzidos ao CCZ e lá se juntavam a outros animais. Passado um determinado prazo, que não era o determinado pela lei, os animais sadios, não reclamados por seus donos, eram exterminados sem qualquer verificação da necessidade de tal procedimento, já que os exames necessários para o diagnóstico de doenças como Leishmaniose visceral canina ${ }^{4}$ não eram realizados.

Segundo o MPMG, os animais (contaminados e sadios) eram submetidos à câmara de gás saturada por monóxido de carbono proveniente do motor de um veículo. Tal fato proporcionava aos animais elevado sofrimento, uma vez que os mesmos não eram, ao menos, sedados. Esse procedimento contraria o Código Sanitário Municipal no 5.616, de 1987, e a Lei Municipal $n^{\circ} 8.565$, de 2003.

Para entender melhor a fundamentação do MPMG, faça-se aqui a primeira observação. O MPMG entendeu que o procedimento adotado pelo órgão municipal contrariou, por completo, a norma trazida pelo Decreto Municipal $n^{\circ} .5 .616$ de 1987, que dispõe sobre a inspeção e fiscalização sanitária municipal em Belo Horizonte.

Segundo o art. 216 e parágrafos do referido decreto, o animal encontrado solto nas vias e logradouros públicos deveria ser apreendido e recolhido ao CCZ, ficando à disposição

\footnotetext{
${ }^{3}$ Procedimento administrativo, nas palavras de Maria Sylvia Zanella Di Pietro, é entendido como o conjunto de formalidades que devem ser observadas para a prática de certos atos administrativos; equivale a rito, a forma de proceder; o procedimento se desenvolve dentro do processo administrativo. Já o processo administrativo, em sentido amplo, define a autora como sendo o conjunto de atos coordenados para a solução de uma controvérsia no âmbito administrativo.

${ }^{4}$ A Leishmaniose Visceral Canina é uma doença grave que afeta não apenas a família dos caninos, mas também outros animais da classe dos mamíferos, por exemplo, o homem. Sua transmissão ocorre por meio do protozoário Leishmania chagasi, que é transmitido por meio da picada do mosquito palha.
} 
do proprietário ou seu representante por dois dias, se pequeno, e cinco dias, sendo de médio ou grande porte. (BRASIL, 1987).

Nesse período, segundo a lei, os animais seriam alimentados e acompanhados por médicos-veterinários. Caso não fossem reclamados, eles seriam submetidos à doação ou, em caso específico, sacrificados - sendo o último caso aplicado aos animais portadores de zoonoses, os condenados por laudo médico e os de origem desconhecida.

Já a Lei Municipal 8565 de 2003, nos artigos 23; 25, II, a e b, dispõe que o animal solto em logradouro público ou de livre acesso ao público, bem como o animal com indícios de contaminação por zoonose, será apreendido e levado ao CCZ. (BRASIL, 2003). O mesmo diploma legal também disciplina que os procedimentos de adoção e sacrifício, previstos no art. 25, deverão ser submetidos à supervisão do médico veterinário do CCZ e consentidos pelas ONGs municipais. Tais exigências legais, segundo o MPMG, não foram respeitadas.

O órgão ministerial salientou que os animais apreendidos só deveriam ser abatidos quando se enquadrassem nas hipóteses do art. 37 da Lei no 9.605, de 1999. A lei mencionada dispõe sobre as sanções penais e administrativas aplicadas às condutas e atividades lesivas ao meio ambiente. O referido diploma legal, no artigo 37, inciso III, dispõe que não é crime o abate de animal nocivo ${ }^{5}$.

O animal portador da Leishmaniose visceral canina é nocivo e representa um perigo para a saúde pública. De acordo com o manual de vigilância e controle da leishmaniose visceral, as leishmanioses são consideradas uma zoonose, podendo afetar o homem quando este entra em contato com o ciclo de transmissão do parasita (Brasil, 2006). O sacrifício dos animais contaminados por essa doença é recomendado. No entanto, conforme a lei acima comentada, a doença deve ser diagnosticada por laudo médico-veterinário. Dessa forma, é razoável a pretensão do MPMG em exigir, para os procedimentos de eliminação de animais portadores de zoonoses, a prévia comprovação de seu contágio por meio do referido laudo.

Outra solicitação feita pelo órgão ministerial foi a alteração do modo adotado pela CCZ para sacrificar os animais contaminados. Pleiteava o Ministério Público, para tal ato (asfixia dos animais por monóxido de carbono - CO), a utilização prévia e adequada de substâncias sedativas.

\footnotetext{
${ }^{5}$ Entenda por nocivo aquilo que "prejudica ou é próprio para causar dano" (Dicionário Aurélio da Língua Portuguesa).
} 
Procede a preocupação ministerial, pois, segundo Cyro Albuquerque Neto (2005), em sua dissertação de mestrado, a inalação de CO por um indivíduo pode causar alteração sutil de comportamento, falhas na visão e alteração nas funções motoras, alterações cardiovasculares, dificuldade visual, cefaleia, dores abdominais, desmaios, paralisias e distúrbios respiratórios e, em casos extremos, bloqueio das funções respiratórias, coma e morte. (NETO, 2005).

No entanto, a denúncia feita pelo MPMG, apesar de trazer ao processo o registro da mídia acerca da adoção, pela municipalidade, de práticas "medievais e abomináveis" e extermínio dos animais de rua, foi julgada improcedente pelo juiz a quo, o que resultou no inconformismo ministerial.

\subsection{DAS CONTRARRAZÕES}

Já o município de Belo Horizonte (recorrido) asseverou que a Lei $\mathrm{n}^{\circ}$ 9.605, de 1998, é destinada à proteção da fauna silvestre não se aplicando, portanto, aos animais domésticos. Também relatou que os animais submetidos ao extermínio eram aqueles cujos donos haviam abandonado e que colocavam em perigo a saúde pública. Dessa forma, compreendeu-se que "as normas constitucionais de proteção à saúde do ser humano devem sobrepor-se às de proteção ao meio ambiente".

O município de Belo Horizonte ainda alegou que o método adotado para sacrificar os animais era um dos mais modernos do mundo, que seus funcionários atuavam em estrito cumprimento do dever legal e que a política adotada para controle de zoonoses era bastante eficaz, pois, desde 1984, não se registrava na capital mineira qualquer caso de raiva humana. Além do mais, justificou que a respeitável sentença foi dada pela improcedência do pedido.

\subsection{A MANIFESTAÇÃO DOS MAGISTRADOS}

Descritos os fatos aduzidos no relatório, passa-se agora para a análise das opiniões manifestadas pelos três desembargadores que atuaram nesse recurso.

\subsubsection{O RELATOR}


Por questões didáticas, a análise do voto proferido pelo Relator será por este artigo dividida em três tópicos, quais sejam, o papel da Administração Pública no entendimento do Des. Relator; a natureza do bem animal e o caráter cruel do tratamento dado aos animais. Dessa forma, adentrando o estudo do mérito, assim entendeu o Relator:

\section{a. O PAPEL dA ADMINISTRAÇÃo PÚBliCA NO ENTENDIMENTO DO DES. RELATOR.}

O Des. Relator iniciou a análise do mérito abordando o Poder de Polícia que a Administração Pública possui, permitindo-a mitigar o exercício de direitos individuais, sob o pretexto de garantir à coletividade o seu bem-estar. Para embasar o seu entendimento, o magistrado citou como fundamento doutrinário o magistério de Maria Sylvia Zanella Di Pietro. Segundo Di Pietro:

Pelo conceito moderno, adotado no direito brasileiro, o poder de polícia é a atividade do Estado consistente em limitar o exercício dos direitos individuais em benefício do interesse público. Esse interesse público diz respeito aos mais variados setores da sociedade, tais como segurança, moral, saúde, meio ambiente, defesa do consumidor, patrimônio cultural, propriedade (DI PIETRO, 2002, p. 111).

O Relator enfatizou que o CCZ da capital mineira atuou no "exercício do poder de polícia sanitária", fiscalizando e realizando ações para o controle e combate de doenças, por exemplo, a Leishmaniose Visceral Canina. Para fundamentar sua posição, o Relator mencionou os dados estatísticos constados na ação civil pública julgada improcedente pela $\mathrm{r}$. sentença. Observe:

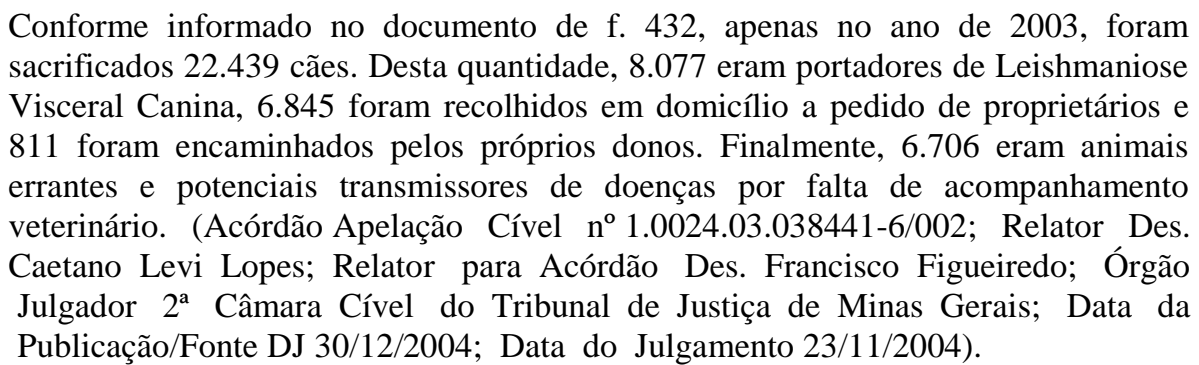

$\mathrm{Na}$ análise da viabilidade de se sacrificar ou não os animais capturados pelo $\mathrm{CCZ}$, ou a ele entregues pelo proprietário, o magistrado concluiu dizendo que ao município não restava 
alternativa senão o sacrifício, seja em decorrência do desejo dos proprietários, seja pelo potencial de risco à saúde pública.

\section{b. A NATUREZA DO BEM ANIMAL}

O julgador, pautando-se no Código Civil de 2002, baseou o seu entendimento na compreensão de que os animais nada mais são do que coisas, ou seja, objetos a serem apropriados: “Acrescento, ainda, que o código civil de 2002 dá aos animais o tratamento de coisas, que podem ficar vagas quer por falta de dono, quer em decorrência de abandono ou renúncia”.

Citando o magistério de Francisco Amaral (2003, p. 309), o Relator prossegue no seu entendimento:

\footnotetext{
É coisa de tudo o que existe no universo e que, sendo útil para a satisfação das necessidades humanas, se torna valioso e, por isso mesmo, objeto de apropriação. Há coisas úteis, mas não apropriáveis, como as coisas comuns, (res communes), a luz, o ar, o mar, o sol, as estrelas. Não são de ninguém e são de todos. E há coisas que embora suscetíveis de apropriação, como os animais de caça, os peixes, coisas abandonadas (res derelictae), não pertencem a ninguém (res nullius). Os animais são coisas, porém objeto de proteção jurídica especial, por si mesmo e como salvaguarda dos sentimentos das pessoas.
}

O Relator ainda asseverou que "os animais recolhidos nas ruas e que não são reclamados no $\mathrm{CCZ}$ por seus donos no prazo legal de quarenta e oito horas, além dos que são voluntariamente entregues na referida repartição pública, são considerados res derelictae”, ou seja, coisa abandonada.

Abrindo-se um parêntese, faz-se necessário compreender, em breves linhas, a origem desse entendimento. É sabido que o ordenamento jurídico brasileiro, como quase a totalidade dos ordenamentos jurídicos dos países pertencentes à América do sul, à Ásia e à Europa, sofreu significativa influência do sistema jurídico romano e alemão, surgindo o sistema romano-germânico. Esse novo sistema jurídico traz, como característica, o rigor da lei para o enfrentamento das complexidades surgidas e desenvolvidas na sociedade.

No campo do direito privado pátrio, especificamente no que concerne ao direito das coisas e da propriedade, profundas foram as influências do direito romano. Este, conforme 
afirmou Carlos Roberto Gonçalves (2012, p. 21), estabeleceu os fundamentos estruturais da propriedade, sob os quais o direito civil moderno edificou suas bases.

Conforme o magistério de Paulo Afonso Leme Machado (2012, p. 908-909), os romanos, em relação à coisa, faziam três distinções: res nullius, (coisas de ninguém ou coisas sem dono); res derelictae, (coisa abandonada ou renunciada) e res communes omnium (coisas comuns passíveis de serem parcialmente apropriadas).

O homem romano, ao disciplinar sua relação com os animais, preocupou-se em estabelecer comandos voltados para a aquisição dos animais e a possibilidade de perda e de desfazimento dessa propriedade. Naquela época, em momento algum tais comandos apresentaram preocupações preservacionistas, como se faz notar:

\begin{abstract}
E adquirimos por direito natural não apenas as coisas tomadas nossas por tradição, mas, também, as adquiridas por ocupação, porque a ninguém pertenciam antes, como todas as coisas apanhadas na terra, no mar e no céu. Por conseguinte, se apresarmos um animal bravio, uma ave ou um peixe, o assim apanhado torna-se logo nosso e entende-se nosso enquanto sujeito à nossa guarda; fugindo-lhe, porém, e voltando à liberdade natural, torna-se novamente do ocupante, pois deixou de ser nosso; e entende-se retornado à natural liberdade, quer escapando à nossa vista, quer, embora à vista, sendo de difícil encalço. Quanto aos animais habituados a ir e voltar, como as pombas, as abelhas, os veados, que costumam ir aos bosques e voltar, temos a regra tradicional: perdendo o hábito de voltar, deixam de ser nossos, tornando-se do ocupante, e consideram-se como tendo perdido o hábito de voltar perdendo o dito costume" (As Institutas de Gaio apud MACHADO, 2012, p. 909).
\end{abstract}

Para o entendimento romano da época, apanhando-se um animal cuja propriedade não era atribuída a ninguém, essa era naturalmente transferida para o apanhador. Esse entendimento ainda é manifestado na atual legislação civil brasileira, em seu art. 1.263: "Quem se assenhorear de coisa sem dono para logo lhe adquire a propriedade, não sendo essa ocupação defesa por lei”. (BRASIL, 2002).

Dessa forma, retomando a análise do voto do Relator, o magistrado, por considerar os animais como coisa abandonada, entendeu no sentido de que cabe ao município de Belo Horizonte, embasado no art. 1263 do Código Civil de 2002, acima citado, o poder de dar a esses animais abandonados a destinação que achar mais conveniente.

\title{
c. O TRATAMENTO DADO AOS ANIMAIS RECOLHIDOS PELO CENTRO DE CONTROLE DE ZOONOSES
}


Observe o texto extraído do acórdão estudado:

\begin{abstract}
No que concerne à questão da crueldade do tratamento dado aos animais e no sacrifício a eles imposto para eliminá-los, a circunstância não restou comprovada. Ademais, a municipalidade realiza os sacrifícios com os meios que possui. E não se vislumbra a necessidade ou a viabilidade de mantê-los vivos, com custos elevados, considerando a realidade social e econômica do país (Acórdão Apelação Cível $\mathrm{n}^{\mathrm{o}}$ 1.0024.03.038441-6/002; Relator Des. Caetano Levi Lopes; Relator para Acórdão Des. Francisco Figueiredo; Órgão Julgador $2^{\mathrm{a}}$ Câmara Cível do Tribunal de Justiça de Minas Gerais; Data da Publicação/Fonte DJ 30/12/2004; Data do Julgamento 23/11/2004).
\end{abstract}

Percebe-se, no trecho citado, que o Relator não se convenceu acerca dos argumentos apresentados pelo MPMG, e desconsiderou a hipótese de crueldade do tratamento dado aos animais recolhidos pelo CCZ da capital mineira.

Sobre o tratamento dados aos animais, atualmente, a doutrina brasileira se divide em duas correntes. Trata-se das correntes abolicionista e reformista que, de forma distinta, na visão de Anamaria Gonçalves Feijó, Cleoas Isaías dos Santos e Natáliza de Campos Grey (2010), trazem o tema ética animal.

Para os autores mencionados, a corrente abolicionista considera os animais irracionais como seres dotados de valor que lhes é próprio, intrínseco, acreditando que os animais possuem fins em si mesmo e, dessa forma, colocam-se contra qualquer utilização, por parte do homem, da espécie animal (FEIJÓ et al., 2010, p. 03). No mesmo sentido, Nathalie Santos Caldeira (2010, p. 647) considera como escravismo a utilização de animais pelo homem, e defende o retorno dos animais a seu habitat, para que possam viver longe dos seres humanos, exercendo o seu direito de liberdade.

Já a corrente reformista busca "defender uma situação de bem-estar animal na criação e uso de animais, aceitando a alteração de determinadas condutas quando essas podem minimizar a dor e o sofrimento do animal" (FEIJÓ et al., 2010, p. 03). Entre as possíveis alterações está a substituição de testes em animais por métodos alternativos.

Baseando na posição de Peter Singer (1990), Feijó et al. (2010, p.03) entenderam que no sofrimento de um ser está o marco para a consideração de seu interesse, como, por exemplo, não ser a ele infligida a dor. Entendem os autores que:

Quanto mais próxima filogeneticamente forem as espécies, maiores serão as semelhanças entre elas, principalmente nas suas estruturas sensíveis. É por essa razão que pelo menos aos animais do subfilo vertebrata é admitida a existência de 
uma capacidade de sentir dor e de sofrer muito similar àquela apresentada pelos humanos (FEIJÓ; SANTOS e GREY, 2010, p.04).

Paulo Afonso Leme Machado (2010, p. 930) entende por crueldade a insensibilidade caracterizada pela indiferença ou prazer proporcionados pelo sofrimento alheio. Já segundo o dicionário da língua portuguesa, cruel significa "que se compraz em fazer mal, em atormentar ou prejudicar" (Dicionário Aurélio).

Retomando o estudo do julgado, com relação ao abrigo desses animais, o Relator ponderou no sentido de que tal medida acarretaria custos elevados para a municipalidade, pois essa não possui meios para tal finalidade e o número de adoções realizadas é inexpressivo em comparação ao número de animais abandonados.

Sendo assim, concluiu o magistrado que, "sem dúvida, foi dado à causa o melhor desate e o inconformismo revela-se impertinente. Com estes fundamentos, nego provimento à apelação." Após manifestar o seu voto, os autos foram encaminhados para a apreciação e voto do Des. Revisor.

\subsection{O REVISOR}

De plano o Des. Revisor já destacou que a r. sentença proferida pelo de MM. Juiz de direito merecia reforma. Segundo o Revisor: "Ao cotejo dos elementos incidentes na questão, tenho que a conclusão sentencial, em parte, está a merecer reparos.”.

Entendendo haver um conflito de direitos, o Revisor iniciou o seu voto dizendo: "No caso, há um conflito de direitos: o direito à vida e preservação dos animais e o direito à saúde e segurança da comunidade, ambos previstos pela Constituição Federal ${ }^{6 \%}$.

O Revisor também manifestou ser favorável ao extermínio de animais em situações determinadas, pois entende "que os animais, de uma maneira geral, devem ser respeitados. Mas a partir do momento que estes se tornam uma ameaça para segurança e saúde da sociedade, estes devem ser retirados do convívio com a comunidade. ”

Semelhante à forma adotada na análise do voto proferido pelo des. Relator, procederse-á também no estudo do voto manifestado pelo magistrado Revisor.

\footnotetext{
${ }^{6}$ A Constituição da República Federativa do Brasil de 1988 estabelece em seu art. $5^{\circ}$, caput, a inviolabilidade do direito à vida. Estabelece também, em seu art. 196, caput, que a saúde é direito de todos e dever do Estado. Essa deve ser garantida mediante políticas sociais e econômicas que visem à redução do risco de doença e de outros agravos.
} 


\section{a. O PAPEL DA ADMINISTRAÇÃo PÚBLICA NO ENTENDIMENTO DO DES. REVISOR.}

No sentido de prevenir a proliferação de doenças, entendeu o Revisor ser a Administração Pública competente para recolher os animais que se encontrarem nas ruas e também sacrificar aqueles que estiverem gravemente doentes, pois esses podem afetar o homem por meio de suas moléstias. Para tal fim, deverá a administração adotar medidas humanitárias, não cruéis, pois a prevenção da proliferação de doenças é legal e moral, e encontra respaldo no art. 196 da CRFB/88 ${ }^{7}$. Trata-se de medida preventiva que visa o nobre fim estatal, o bem-estar.

Entende o magistrado que o agente público deve agir em conformidade com os preceitos da boa administração e que "os animais apreendidos pelo Poder Público não sejam sacrificados, ou, se forem, que seja por decisão alicerçada em laudo firmado por veterinário, inclusive com comunicação prévia ao órgão ministerial local."

Note que o entendimento do Des. Relator segue o disposto na Lei 5616 de 1997, que dispõe sobre a inspeção e fiscalização sanitária municipal em Belo Horizonte, e, também, na Lei Municipal 8565 de 2003, ambas já comentadas neste artigo.

Reforça o Revisor que "essa prática deve ser regularizada e controlada, para que, em nome da saúde pública, não se viole o direito à proteção constitucional do animal, consagrada e cristalizada no art. 225, par. $1^{\circ}$, inciso VII, CF”. Fundamentado no Decreto Lei 24645/34, o magistrado disse não poder serem tais atos suportados pela administração pública, pois os mesmos configuram uma violação ao mesmo.

$\mathrm{O}$ art. $3^{\circ}$ do referido decreto considera maus-tratos as práticas de atos que caracterizem abuso ou crueldade a qualquer animal, sua manutenção em locais anti-higiênicos, que impeçam a respiração, o movimento ou o descanso, ou os privem de ar ou luz. O artigo citado também considera maus-tratos não proporcionar ao animal, que necessitar, uma morte rápida, sem sofrimento.

\footnotetext{
${ }^{7}$ Dispõe a Constituição Federal brasileira de 1988 no seu art. 196, caput, que a saúde é direito de todos e dever do Estado, a ser garantido mediante políticas sociais e econômicas que visem à redução do risco de doença e de outros agravos, e acesso universal e igualitário às ações e serviços para sua promoção, proteção e recuperação (Brasil, 1988).
} 
Outro diploma legal suscitado pelo magistrado foi a Lei 9.605/98. Tal diploma, no seu art. 32, considera crime "Praticar ato de abuso, maus-tratos, ferir ou mutilar animais silvestres, domésticos ou domesticados, nativos ou exóticos” (BRASIL, 1998), estabelecendo, além da multa, pena de detenção de três meses a um ano.

O Des. Revisor, ao fundamentar o seu voto na necessidade de a Administração Pública observar a lei, obriga este trabalho a tecer alguns comentários acerca da relação existente entre os atos administrativos a serem realizados pela Administração Pública e a lei que os norteia.

Abrindo outro parêntese no estudo do acórdão em análise, os atos administrativos, na visão de Hely Lopes Meirelles (2010, p. 153), podem ser definidos como "toda manifestação unilateral de vontade da Administração Pública que, agindo nessa qualidade, tenha por fim imediato adquirir, resguardar, transferir, modificar, extinguir e declarar direitos, ou impor obrigações aos administrados ou a si própria”.

Já Maria Sylvia Zanella Di Pietro ensina que o ato administrativo seria "a declaração do Estado ou de quem o represente, que produz efeitos jurídicos imediatos, com observância da lei, sob regime jurídico de direito público e sujeita a controle pelo Poder Judiciário (DI PIETRO, 2010, p. 198)".

Nota-se nas duas definições acima que trata-se o ato administrativo de uma declaração ou manifestação de vontade proveniente do Estado. No entanto, para que essa vontade/declaração da Administração Pública tenha validade, segundo Di Pietro (2010, p. 198), é necessário que a mesma observe a lei, satisfazendo o princípio da legalidade que rege todo o ordenamento jurídico brasileiro.

Com isso é possível chegar ao entendimento de que o Poder Público, ainda que exerça atividades atribuídas em lei, ou com margem de liberdade por ela permitida, não poderá exercê-las desrespeitando, ultrapassando os limites legais e morais impostos à atividade administrativa. Se assim o fizer, a Administração estará ferindo os princípios constitucionais da legalidade e da moralidade, conforme o art. 37, caput, da CRFB/88.

Ocorrendo o desrespeito aos princípios da legalidade e da moralidade, caberá à própria Administração Pública, com base no princípio administrativo da autotutela, exercer o controle sobre os próprios atos, podendo anular os ilegais e revogar os inconvenientes ou inoportunos 
(DI PIETRO, 2010, p. 69). Na hipótese de atos ilegais, estes poderão ser anulados também pelo Poder Judiciário, no exercício do controle externo ${ }^{8}$.

No caso em estudo, o Revisor, ao citar os instrumentos legais que tratam da proteção dos animais, entende que Administração Pública está a eles vinculada, devendo pautar suas ações em estrita obediência a esses instrumentos.

Retornando para o estudo do acórdão, o Desembargador Revisor fez algumas considerações:

[...] a verdade, porém, é que princípios - seja o da discricionariedade, seja o da proteção à saúde - não podem ser invocados para cometer crimes, pois sua elasticidade a tanto não chega. Se a lei - autorizada pela Constituição (art. 225, par. $3^{\circ}$ ) - diz ser crime o extermínio de animais, não existe escolha possível. A discrição administrativa é essencialmente legal, pois desde SEABRA sabe-se que "administrar é aplicar a lei de ofício". Em outros termos: invocar discricionariedade para praticar atos que a lei conceitua como ilícitos é absolutamente inconcebível, ainda que, de forma irônica, sejam tais atos qualificados como "eutanásia" (Acórdão Apelação Cível no 1.0024.03.038441-6/002; Relator Des. Caetano Levi Lopes; Relator para Acórdão Des. Francisco Figueiredo; Órgão Julgador $2^{\mathrm{a}}$ Câmara Cível do Tribunal de Justiça de Minas Gerais; Data da Publicação/Fonte DJ 30/12/2004; Data do Julgamento 23/11/2004).

O magistrado, ao citar SEABRA, reforça o preceito de que a Administração Pública, ao tratar de ato vinculado, deve aplicar a lei, não podendo dela desviar-se, em respeito ao princípio da legalidade. Da mesma forma, no ato discricionário, a Administração, mesmo com uma margem de liberdade dada pela lei, deverá caminhar nos limites por ela impostos, sob pena de utilizar a discricionariedade administrativa para cometer ilicitudes.

Sendo assim, no que se refere ao papel da Administração Pública, concluiu o Revisor que a teoria atual do Direito Administrativo tem como base a conjugação da norma com os princípios do Direito, objetivando construir um sistema mais humanitário para todos.

\section{b. QUANTO AO TRATAMENTO DADO AOS ANIMAIS RECOLHIDOS}

Por fim, acrescentando em seu voto revisor, o magistrado trouxe à discussão a Declaração Universal dos Direitos dos Animais (1978), que diz: "se a morte de um animal é

\footnotetext{
${ }^{8}$ Tanto o controle interno, aquele realizado pela própria Administração no exercício do princípio da autotutela, quanto o controle externo, configurado pelo controle exercido por um poder sobre o outro, tem como finalidade garantir que um ato administrativo seja realizado em consonância com os princípios constitucionais previstos no art. 37 da $\mathrm{CRFB} / 88$, quais sejam, os princípios da legalidade, impessoalidade, moralidade, publicidade e eficiência
} 
necessária, deve ser instantânea, sem dor e sem angústia [...] o ato que leva à morte de um animal sem necessidade é um biocídio, ou seja, um delito contra a vida” (BÉLGICA, 1978).

Em seu voto, para tentar resolver os problemas que envolvem os animais de rua e os apreendidos, o Revisor sugeriu, ao Poder Público e à sociedade civil, implantar um programa de castração, e, para os animais abandonados, o desenvolvimento de uma consciência de adoção e não de abandono desses animais. Nos casos em que os animais estiverem acometidos de doenças graves, tais como a Leishmaniose Visceral Canina, a raiva e outras doenças incuráveis e potencialmente perigosas para a saúde pública, o Revisor é favorável a submetê-los, quando estritamente necessário, ao sacrifício, utilizando-se da correta eutanásia.

O magistrado orientou que "o sacrifício de qualquer animal apreendido será realizado mediante aplicação endovenosa de medicamento que leva à morte rápida e sem sofrimento para o animal", e considerou ilegal, cruel, inverossímil e sem cabimento o ato municipal que determinou a apreensão e o posterior abatimento dos animais que fossem enquadrados como de origem desconhecida pelo CCZ.

Para o magistrado, não só o clamor da Sociedade de Proteção aos Animais, o registro da imprensa, despertando no público o repúdio aos critérios adotados para o abate desses animais, e os diversos testemunhos prestados demonstraram crueldade e desumanidade em tais atos. Esse comportamento cruel e desumano, continua o magistrado, não deve ser admitido, tolerado pela Administração Pública Municipal, pois o mesmo contraria a Carta Magna de 1988 e, como consequência, fere as normas dela decorrente.

Dessa forma, o Des. Revisor redobra a necessidade de se proceder ao extermínio dos animais com estrita observância aos critérios legais, e proveu parcialmente o recurso, utilizando os seguintes termos:

Somente em parte - mas relevante - merece reforma a decisão, pelo que, curvandome com redobrada vênia do respeitável ponto de vista do douto Relator, DOU PARCIAL PROVIMENTO ao recurso, apenas para assegurar que nas hipóteses em que a eliminação dos animais seja necessária, de acordo com decisão fundada em laudo veterinário, seja então a medida adotada com prévia e regular sedação (Acórdão Apelação Cível n 1.0024.03.038441-6/002; Relator Des. Caetano Levi Lopes; Relator para Acórdão Des. Francisco Figueiredo; Órgão Julgador $2^{\mathrm{a}}$ Câmara Cível do Tribunal de Justiça de Minas Gerais; Data da Publicação/Fonte DJ 30/12/2004; Data do Julgamento 23/11/2004). 
Dando sequência à análise do julgado em estudo, passa-se para o voto proferido pelo Vogal que compôs a câmara julgadora.

\subsubsection{O VOTO DO VOGAL}

O desembargador iniciou o seu voto manifestando a necessária preocupação com as atividades caracterizadoras de maus-tratos e morte de animais, bem como o seu confinamento e sacrifício pelo Centro de controle de Zoonoses.

A preocupação manifesta pelo vogal condiz com os já citados incisos II e IV do art. $3^{\circ}$ do decreto lei 24645/34, que consideram maus tratos a manutenção de animais em lugares que lhes impeçam de respirar, movimentar, descansar, que lhes privem o ar ou a luz; bem como o sacrifício lento e doloroso.

Segundo o magistrado, para garantir não só a saúde dos animais, mas, principalmente, a saúde dos seres humanos, o ideal encontra-se na adoção das recomendações do $8^{\circ}$ Informe Técnico da Organização Mundial de Saúde, que apresenta medidas de prevenção como, por exemplo, a vacinação, a esterilização e fiscalização da educação para posse dos animais. $\mathrm{O}$ desembargador, sensibilizando-se com a realidade vivida pela Administração Pública, salientou:

\footnotetext{
Contudo, com os olhos voltados para a realidade socioeconômica de nosso País, observamos a ausência de recursos capazes de adoção de uma política pública eficaz, para reconhecer também o direito dos animais, mas no sonho espera-se que esta proteção de avanço da ação da polícia sanitária seja capaz de impedir futuramente o sacrifício dos animais domesticados e não domesticados (Acórdão Apelação Cível no 1.0024.03.038441-6/002; Relator Des. Caetano Levi Lopes; Relator para Acórdão Des. Francisco Figueiredo; Órgão Julgador $2^{\mathrm{a}}$ Câmara Cível do Tribunal de Justiça de Minas Gerais; Data da Publicação/Fonte DJ 30/12/2004; Data do Julgamento 23/11/2004).
}

Dessa forma, não desconhecendo a escassez de recursos vividos pelo Poder Público, tanto na esfera municipal, quanto nas demais esferas administrativas, mas que, do contrário, os permitiriam adotar medidas definitivas e que satisfariam os anseios de todas as pessoas envolvidas, o magistrado solicitou a devida vênia ao des. Relator e acompanhou o voto proferido pelo Des. Revisor. 


\section{ALGUMAS CONSIDERAÇÕES E CONCLUSÃO}

Nesse breve estudo de caso, foi abordado o tratamento destinado aos animais apreendidos e levados ao Centro de Controle de Zoonoses de Belo horizonte. Nessa análise, é possível perceber a fragilidade dos argumentos utilizados pela Administração Pública municipal quando teve suas práticas questionadas no Poder Judiciário mineiro.

Pautando-se em fundamentos positivistas, ultrapassados, estritamente privatistas e utilitaristas, a Administração Pública municipal valeu-se de argumentos como: a Lei 9605/98 não se aplicaria aos animas domésticos, uma vez que o referido diploma tutela a fauna silvestre; o método utilizado pelo CCZ, além de ser o único que possuía, era um dos mais modernos; e, o mais fraco e antiquado dos três, a Administração fundamentou-se na ideia de que os animais abandonados e os infectados são considerados como coisa sem dono, coisa abandonada (herança da Roma antiga) e, portanto, poderia o município dar a eles o destino que bem lhe aprouver.

Vale ressaltar que o instituto coisa (res) é, quando muito, tutelado pelo direito sem se caracterizar como sujeito de direito. Os animais, por outro lado, não podem ser considerados como coisas, uma vez que eles possuem direitos atribuídos pela própria Constituição Federal de 1988. Reza o texto constitucional, em seu art. 225 , §1 $1^{\circ}$, VII, que os animais têm direito a não ser submetidos à tortura, a maus tratos e às práticas cruéis. $\mathrm{Na}$ atualidade, a problemática que os envolve vai além de simples classificações trazidas em um texto legal, pois vem superar tacanhas interpretações que se limitam a observar aquilo que é ou não abrangido por uma lei.

No direito moderno, pautando-se em conhecimentos científicos e se sustentando em pilares constitucionais, a tutela jurídica dos animais caminha no sentido de serem eles classificados como sujeitos de direitos, rompendo com antiga e obsoleta ideia civilista de animal como coisa. Dessa forma, busca-se a compreensão no sentido de que a fauna (silvestre ou doméstica), independentemente de haver especificidade legal, trata-se de seres sencientes, possuidores da capacidade de sentir dor, tristeza, alegria e prazer, pois o fato de serem abandonados, estarem infectados e vagarem pelas ruas dos centros urbanos, não desnatura sua condição de ser e, tampouco lhes retiram a capacidade de sentir as sensações acima descritas. 
É bom salientar que o texto constitucional não fez nenhum tipo de distinção entre fauna doméstica e fauna silvestre. Se a Lei maior não especificou de forma limitativa a tutela das espécies faunísticas, menos ainda poderia fazer a Lei infraconstitucional. E, seguindo essa lógica, o caput do art. 32 da Lei 9605/08 considera crime praticar ato de abuso, maus-tratos, ferir ou mutilar animais silvestres, domésticos ou domesticados, nativos ou exóticos.

Para esse artigo, em análise dos fatos narrados no Acórdão comentado, os mesmos demonstraram, de forma evidente, a crueldade constada na prática realizada pelo município de Belo Horizonte, por meio de seu centro de controle de zoonoses, ao alojar esses animais abandonados e, posteriormente, sacrificá-los, causando-lhes grande sofrimento.

Chega a ser espantoso, para aqueles não familiarizados com o direito pátrio, deparar com situações em que a própria Administração Pública viola preceitos constitucionais, no entanto, para os estudiosos e operadores do direito, tal situação é comum. A título de exemplo, a Lei 6.638/79 autoriza práticas cruéis como a vivissecção de animais; há pouco tempo, eram permitidas, a pretextos da cultura, práticas cruéis cometidas aos bovinos na tradicional festa denominada farra do boi, chegando ao absurdo de o órgão legislativo catarinense tentar legalizar essa prática, contrariando decisão já manifestada pelo Supremo Tribunal Federal. Também é possível encontrar vereadores brasileiros envolvidos em brigas de galo, práticas de rodeios patrocinadas por municípios no interior desse Brasil, circos, zoológicos e outros exemplos que demonstram a falta seriedade que as autoridades brasileiras demonstram, quando o assunto é a proteção dos animais.

Por fim, para concluir, esse artigo não pretende elevar a situação jurídica dos animais à condição de seres humanos. Entende esse trabalho que cabe ao direito regular as relações sociais através da imposição de normas e da estipulação de condutas, pautando-se, é claro, em conhecimentos, princípios e valores consagrados e demonstrados pela sociedade. Sendo assim, considera-se muita pretensão do mesmo ignorar a Biologia ou querer mudar suas leis. Os animais, conforme essa ciência, em muito se assemelham aos homens, pois, são seres bióticos e sencientes, ajudando a compor a biota e equilibrar as funções ecossistêmicas do planeta.

Os animais, tanto quanto os homens, são merecedores de condições básicas de sobrevivência, respeito e dignidade, aduzidas, dessa maneira, no preâmbulo da Declaração Universal dos Direitos dos Animais. Do julgado analisado, pode ser extraído o ensinamento de que não cabe a ninguém, tampouco à Administração Pública, eximir-se do respeito aos 
animais. Considerar os seres viventes como coisa de ninguém para, em nome da discricionariedade administrativa, dar-lhes o fim que julgar pertinente, não é oportuno e tampouco conveniente.

A prática de extermínio de animais efetuados pelo município de Belo Horizonte, mesmo sendo esses portadores de doenças incuráveis e transmissíveis aos homens, conforme quis justificar a municipalidade, está longe de caracterizar eficiência. Essa prática foi acertadamente classificada pelo Revisor como descabida, ilegal e cruel, sendo intolerável sua realização por qualquer pessoa, quanto mais pela Administração Pública, que é detentora do dever de cumprir as leis.

Sendo assim, pertinentes foram os votos proferidos pelos desembargadores. Eles entenderem ser inadmissível e cruel a prática de extermínio adotada pelo Município de Belo Horizonte, prevalecendo o respeito à dignidade dos animais não humanos ao afastar, nesse caso específico, a irracionalidade dos homens. Tal decisão soma-se às demais jurisprudências favoráveis à proteção do animal, fortalecendo o entendimento doutrinário a esse respeito.

\section{REFERÊNCIAS}

BELGICA, Declaração Mundial dos Direitos dos Animais. 1978. Disponível em < http://www.propq.ufscar.br/comissoes-de-etica/comissao-de-etica-na-experimentacaoanimal/direitos $>$. Acessado em 09 maio 2015.

BRASIL, Constituição (1988). Constituição da República Federativa do Brasil de 1988. Brasília: Senado Federal, 1988.

BRASIL. Decreto municipal nº 5.616 de 1987. Dispõe sobre a inspeção e fiscalização sanitária municipal em Belo Horizonte.

BRASIL. Decreto-Lei no. 24.645 de 1934. Estabelece medidas de proteção aos animais. BRASIL. Lei 5197 de 03 de Janeiro de 1967. Dispõe sobre a proteção à fauna e dá outras providências.

BRASIL. Lei municipal $n^{\circ} .8 .565$ de 2003. Dispõe sobre o controle da População de cães e gatos e dá outras providências.

BRASIL. Lei 9.605 de 12 de Fevereiro de 1998. Dispõe sobre as sanções penais e administrativas derivadas de condutas e atividades lesivas ao meio ambiente, e dá outras providências.

BRASIL. Lei 10.406 de 10 de Janeiro de 2002. Código Civil Brasileiro. 
BRASIL. Lei 11794 de 08 de Outubro de 2008. Regulamenta o inciso VII do $§ 1^{\mathrm{o}}$ do art. 225 da Constituição Federal, estabelecendo procedimentos para o uso científico de animais; revoga a Lei n⿳ำ 6.638, de 8 de maio de 1979; e dá outras providências.

Brasil. Ministério da Saúde. Secretaria de Vigilância em Saúde. Departamento de Vigilância Epidemiológica. Manual de vigilância e controle da leishmaniose visceral / Ministério da Saúde, Secretaria de Vigilância em Saúde, Departamento de Vigilância Epidemiológica. Brasília: Editora do Ministério da Saúde, 2006.

BRASIL. Instituto Brasileiro de Meio Ambiente e Recursos Renováveis. Portaria nº 93, de 07 de julho de 1998, publicada em 08 de julho de 1998.

BRASIL. Superior Tribunal de Justiça. Recurso Especial no. 1.115.916/MG. Disponível em <HTTP://www.stj.jus.br>. Acesso em: 02 de Abr. 2014.

BRASIL. Tribunal de Justiça do Estado de Minas Gerais. Apelação Cível $\mathrm{n}^{\circ}$ 1.0024.03.038441-6/002. Relator Des. Caetano Levi Lopes, julgado em 23/11/2004.

DI PIETRO, Maria Sylvia Zanella. Direito Administrativo. 23 ${ }^{a}$ Ed. São Paulo: Editora Atlas, 2010.

FEIJO, Anamaria Gonçalves; SANTOS, Cleopas Isaías; GREY, Natália de Campos. O animal não humano e seu status moral para a ciência e Direito ao cenário brasileiro. Revista de Bioéticas y Derecho. No 19, Maio 2010.

FERREIRA, Aurélio Buarque de Holanda. Dicionário Aurélio Básico da Língua Portuguesa. Rio de Janeiro: Nova Fronteira.

GOMES, Nathalie Santos Caldeira. Ética e Dignidade Animal: Uma abordagem da Constituição Brasileira, da Lei de Crimes Contra a Natureza e do Decreto de Proteção aos Animais sob a Ótica da Declaração Universal dos Direitos dos Animais. XIX Encontro Nacional do CONPEDI, Fortaleza, p.645-655, 2010.

GONÇALVES, Carlos Roberto. Direito Civil brasileiro, Vol. 5: direito das coisas - 7 Ed. São Paulo: Saraiva, 2012.

MACHADO, Paulo Afonso Leme. Direito Ambiental. 20 Ed. São Paulo: Editora Malheiros, 2012.

MEIRELLES, Hely Lopes. Direito Administrativo Brasileiro. 36 ${ }^{\text {a }}$ Ed. São Paulo: Editora Malheiros, 2010.

MILARÉ, Edis. Direito do Ambiente: A Gestão Ambiental em foco: doutrina, jurisprudência, glossário. $7^{a}$ Ed. São Paulo: Editora Revista dos Tribunais, 2011.

NETO, Cyro Albuquerque. Um Modelo de Transporte de Monóxido de Carbono no Sistema Respiratório do Corpo Humano. 2005. 142 f. (Dissertação de Mestrado em Engenharia) Escola Politécnica da Universidade de São Paulo, 2005. 
Revista da Faculdade de Direito-RFD-UERJ - Rio de Janeiro, n. 29, jun. 2016

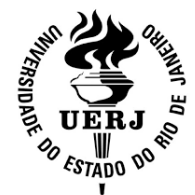

Pág in a | 214

SILVA, José Afonso da. Direito Ambiental Constitucional. $7^{\text {a }}$ Ed. São Paulo: Editora Malheiros, 2009.

SILVA, Luciana Caetano da. Fauna terrestre no direito penal brasileiro. Belo Horizonte: Editora Mandamentos, 2001. 